\title{
Effectiveness of Reality Therapy on Empathy of the Spouses of Veterans With Post-Traumatic Stress Disorder
}

Hojjati. $\mathrm{H}^{1}$

Habibi. $\mathrm{K}^{2}$

*Alimohammadzadeh. $\mathrm{KH}^{3}$

1. Ph.D. in Nursing, Assistant Professor, Nursing Department, Ali Abad Katoul Branch, Islamic Azad University, Ali Abad Katoul, Iran.

2. MSc Student, Nursing Department, Tehran Medical Sciences Branch, Islamic Azad University, Tehran, Iran.

3. ( ${ }^{*}$ Corresponding Author) Ph.D. in Health Services Management, Associate Professor, Health Services Management Department, Faculty Management and Social Sciences, North Tehran Branch, Islamic Azad University, Tehran, Iran. Email: dr_khalil_amz@yahoo.com

\section{Abstract}

Introduction: The Spouses of Veterans With Post-traumatic Stress Disorderbecause of frequent contact with her husband during their life have been greatly affected by emotional-spiritual problems, which often have a vague concept of love and empathy

Objective: According to the theory of Glasser's Reality Therapy to improve marital relations, this study conducted to survey the effects of reality therapy on the empathy of post-traumatic stress disorder in Spouses of war veterans.

Materials and Method: Using randomized sampling, thisexperimental study was conducted on 34 war veterans with post-traumatic stress disorderin Nyayesh hospital in Tehran in 2015 that were assigned to 2 groups ofexperimental $(\mathrm{n}=17)$ and control ( $\mathrm{n}=17)$. Experimental group receivedeight 90-120 minute sessionsof reality therapy based on Glasser's Theory. Standardized empathy questionnaire (Davis) questionnaire wasemployed to collect data before and after the intervention. Then, data were analyzed by paired and independent $t$ tests.

Results: The mean and standard deviation (Mean $\pm \mathrm{SD}$ ) of empathy in reality therapy groupbefore the interventionwas $61.01 \pm 15.01$ and in the control groupwas 53.52 \pm 13.1 ; independent $t$-test showed no significant difference $(\mathrm{P}=0.13)$. Butthe mean and standard deviation (Mean $\pm \mathrm{SD}$ ) of empathy in reality therapy group was $73.47 \pm 9.2$ after the intervention, and in the control group was $59.29 \pm 1.7$. That shows a significant difference $(\mathrm{P}=0.003)$. Thus,empathy in the intervention group was more than that in the control group.

Discussion and Conclusion: According tothe effectiveness of this approach on increasing the empathy of veterans' spouses, it is suggested that officials and health professionals, especially nurseimprove the quality of life in the families of veterans 'spouses by understanding the needs of veterans' spouses and familiesand holding workshops and training classes andand group therapy sessions based on reality therapy.

Keywords: Empathy, Post-Traumatic, Reality Therapy, Stress Disorder, Veterans.

IRCT No.: IRCTN1R229059 


\title{
تأثير واقعيت درمانى بر همدلى همسران جانبازان دجار اختلال استر سي إز سانحه جنكى
}

\author{
حميد حجتى'، كامليا حبيبى'،"خليل على محمدزاده
}

جـكيده

مقدمه: همسران جانبازان دجار اختلال استرس يُ از سانحه جنَ به دليل تماس مكرر در طول زندگى با همسران خود

دجار مشكلات عاطفى و روحى زيادى مىشوند كه اغلب در زندگى آنها عشق و همدلى مفهومى كَنَ دارد. هدف: با توجه به ماهيت نظريه واقعيت درمانى كلاسر بر بهبود روابط زناشويى اين مطالعه با هدف تأثير واقعيت درمانى بر همدلى همسران جانبازان اختلال استرس يس از سانحه جنكى انجام شد.

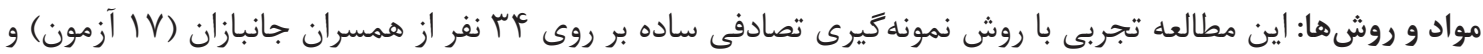

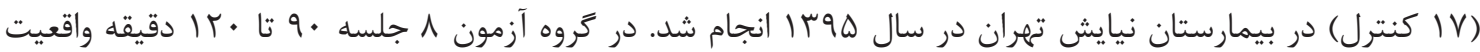

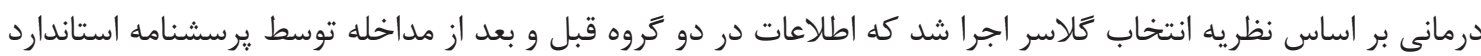

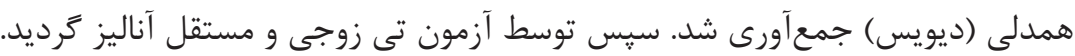

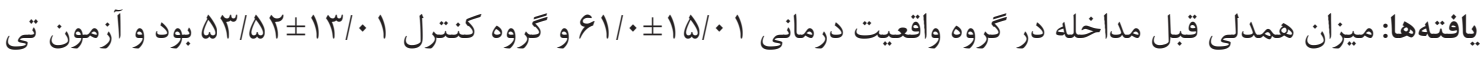

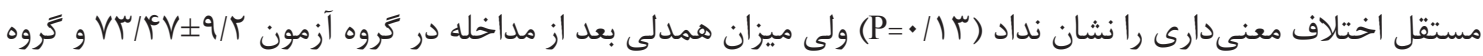
كنترل 1/1/ كروه آزمون بيشتر از كروه كنترل بود. بحث و نتيجه تيرى: نظر به اثربخشى اين رويكرد در افزايش همدلى همسران جانبازان بيشنهاد مى گردد، مسئولين و دستاندر كاران نظام بهداشتى و درمانى به خصوص :برستاران با دركى نياز همسران و خانوادههاى جانبازان و بركزارى كار كاهها و كلاسهاى آموزشى و جلسات كروه درمانى مبتنى بر واقعيت درمانى ضمن تقويت روابط زناشويى، موجب بهبود كيفيت زندىى در خانواده همسران جانبازان شوند. كلمات كليدى: اختلال استرس يّ از سانحه جنكى، واقعيت درمانى، همدلى، همسران جانبازان. كد كار آزمايى بالينى: DQ • IRCTNIRTYq

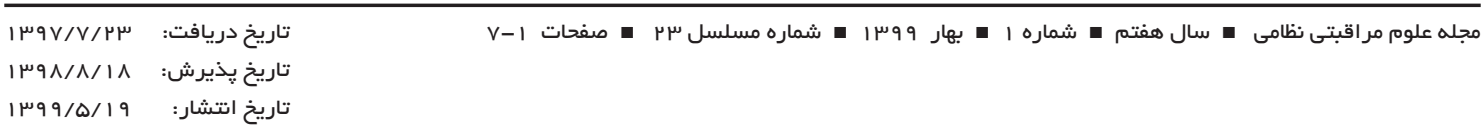

و تماسهاى مكرر با جانبازان مشكلات عاطفى، جسمى و روانى زيادى را تجربه مىنمايند (أ، ف). زيرا اضافه شدن نقش مراقبتى اختلال استرس ڤِ از سانحه رايجترين اختلال روانى در سربازان

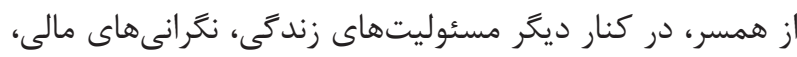

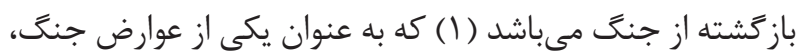
كاهش حمايتهاى اجتماعى، افزايش نياز فرزندان، فقدان امنيت اثرات منفى بر روى خانواده و همسر ان مصدومين جنكى مى گذارد در خانواده، موجب ترس، نكرانى و اختلال در عملكرد خانواده

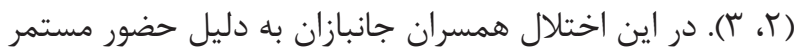


تا دريابد كه اجراى واقعيت درمانى به شيوه كروهى خه تأثيرى بر

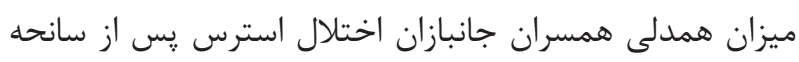

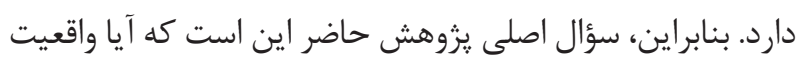

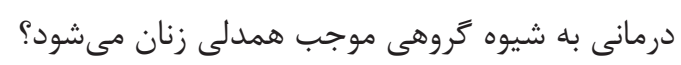

\section{مواد و روشها}

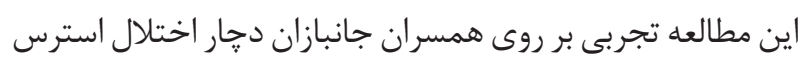

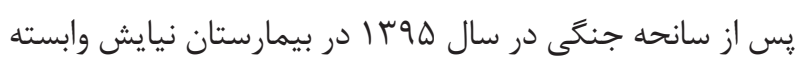

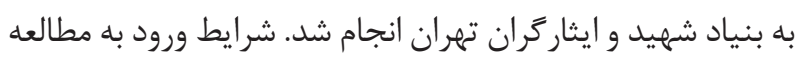

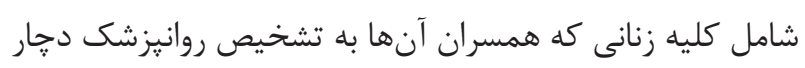

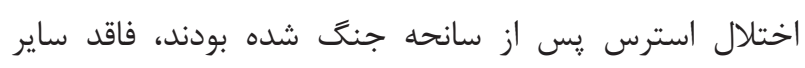
جانبازىهاى ديكر نظير (شيميايى، قطع عضو، قطع نخاع...)،

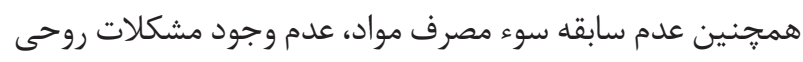

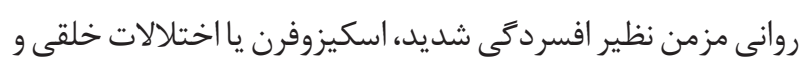

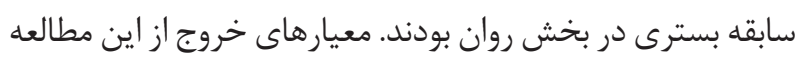

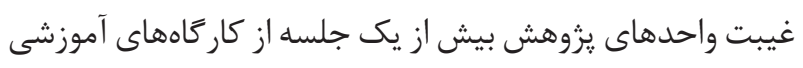
و انصراف واحدهاى يزوهش از شركت در مطالعه مى باشند.

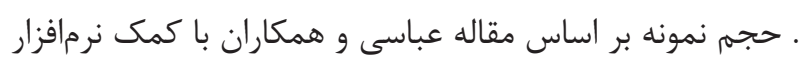

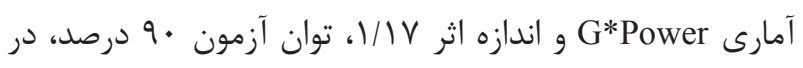

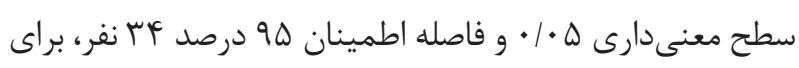

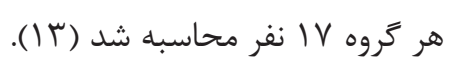

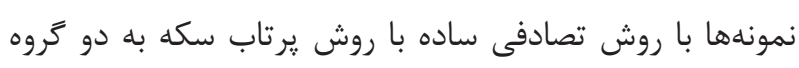

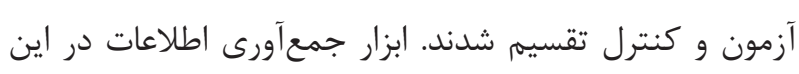
مطالعه دو يرسشنامه مشخصات جمعيت شناختى (سن، درصد

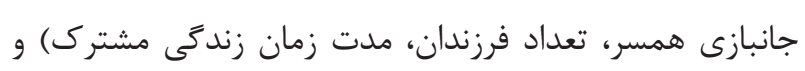

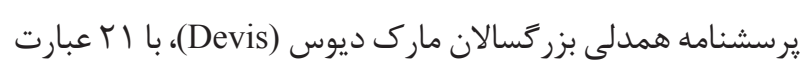

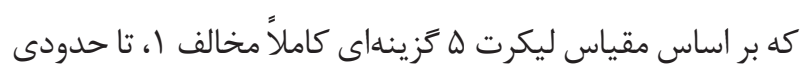

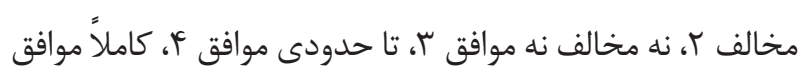

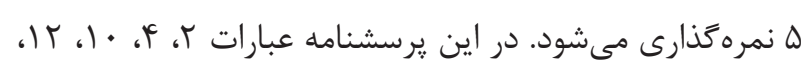

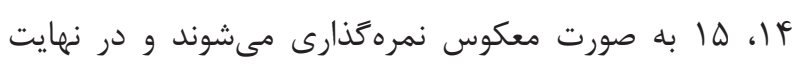

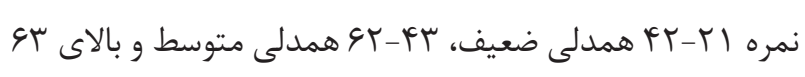

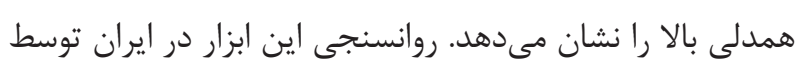

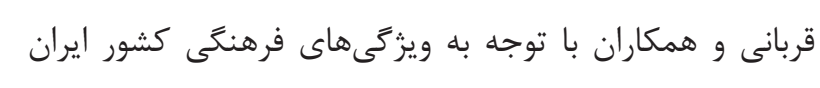

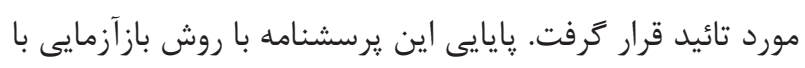

مى گردد (Y، V). اين مسئله سبب بروز و تشديد مشكلات اجتماعى

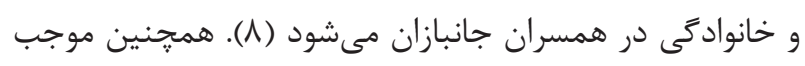
كاهش حس همدلى به عنوان يك نياز اساسى در روابط زوجين

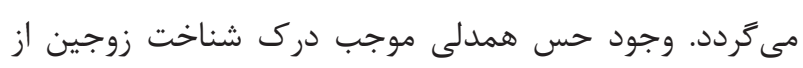

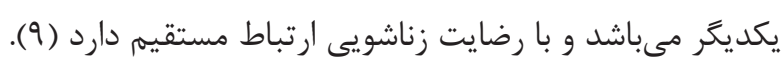

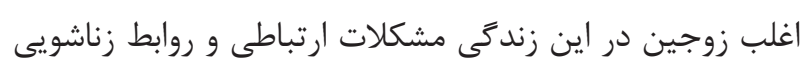

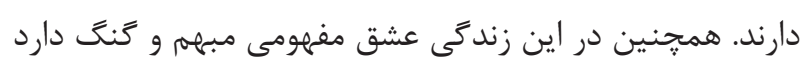

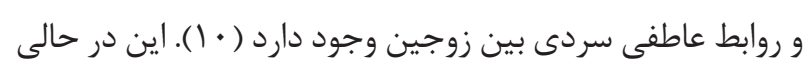

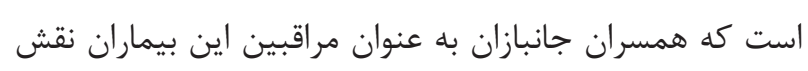

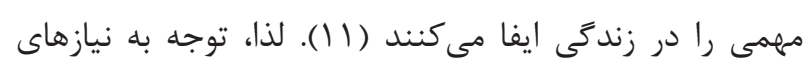
بهداشتى و سلامت روان همسران جانبازان استرس يس از سانحه به ريه عنوان يك ضرورت براى برنامهريزى برنامههاى مراقبتى محسوب

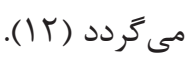
يكى از نظريههايى كه در مطالعه روابط زناشويى و يايدارى ازدواج

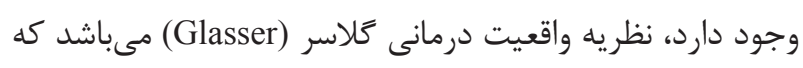
در آن بهترين راه درمان مشكلات زناشويى تغيير رفتار از طريق نطريق

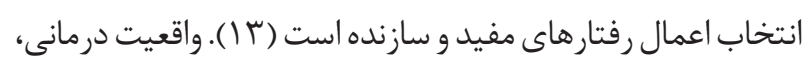

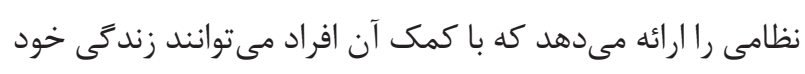

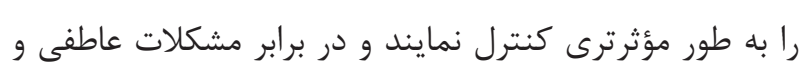

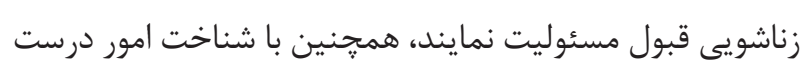

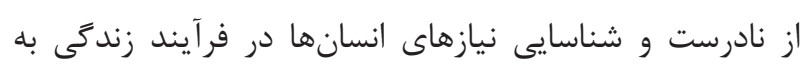

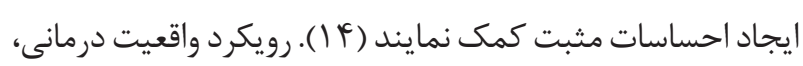
موجب قبول واقعيتهاى زندگى، يذيرش مسئوليتها و كنترل

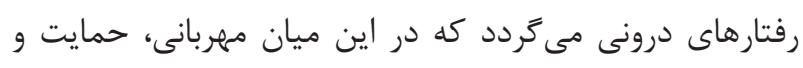

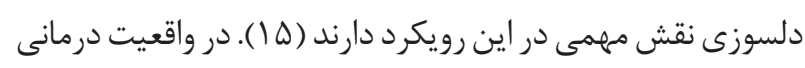
نقش مشاور بيشتر آموزشى و تربيتى است تا درمانى و بهتر دينر

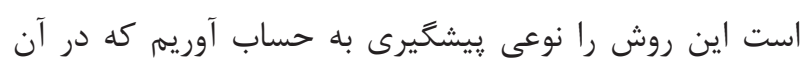

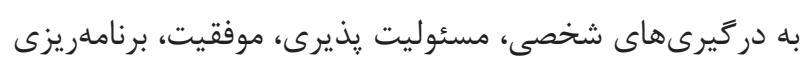

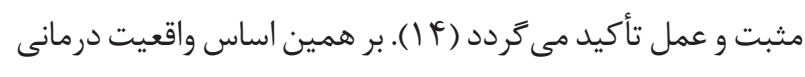

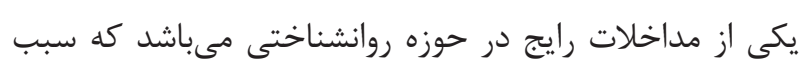

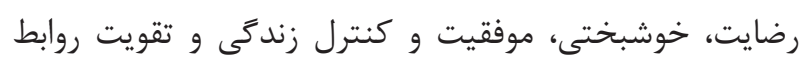

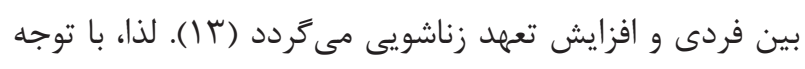
به اينكه يزوهشى با هدف تعيين تأثير واقعيت درمانى بر ميزان

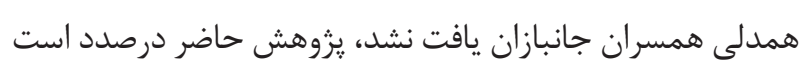


اولين جلسه اطلاع داده شده بود كه در صورت غيبت بيش از

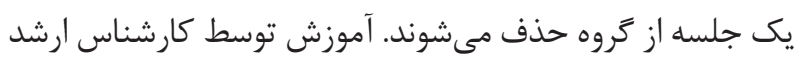

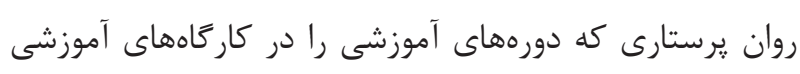

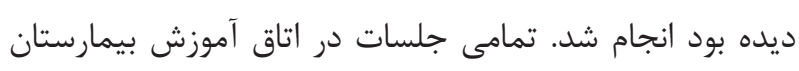
اجرا شود. تمامى جلسات همراه با تكليف خانتى و ارائه بروشور آموزشى بود. در طول مطالعه تمامى مشاركت كنند

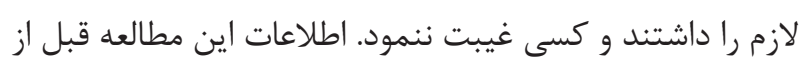

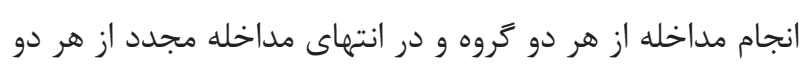

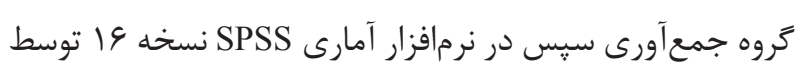

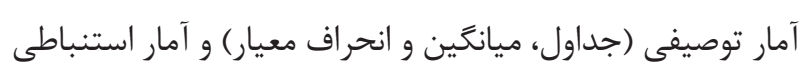

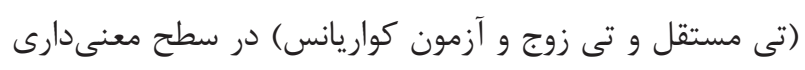

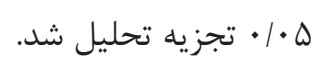

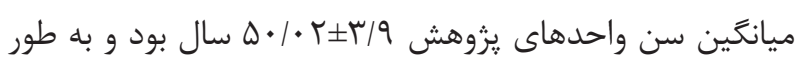
ميانگين، نمونهها

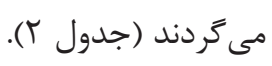

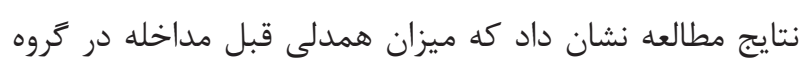

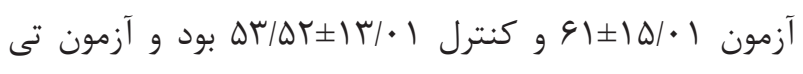

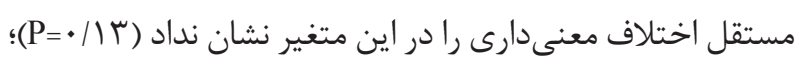

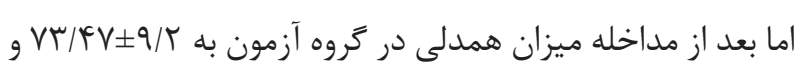

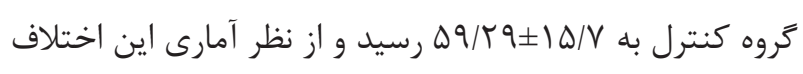

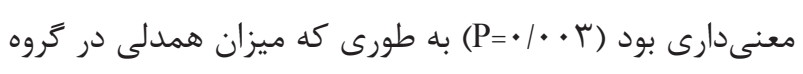

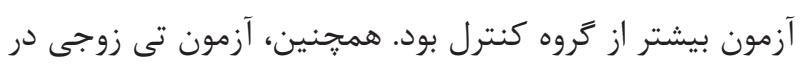
كروه كنترل، قبل و بعد از مداخله اختلاف معنى دارى در ميزان
ضريب همبستخى 1/99• مورد تائيد قرار كرفت (19). همجنين

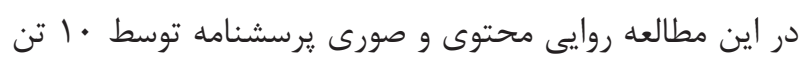
از اعضاى هيئت علمى دانشخاه آزاد اسلامى انجام شد. يايايى ابزار

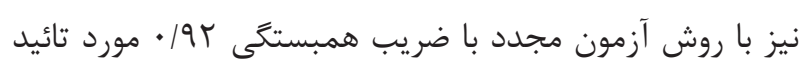

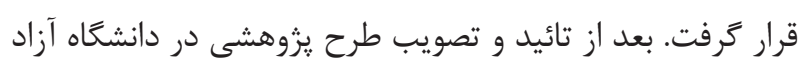

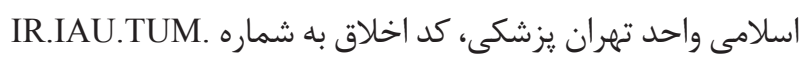

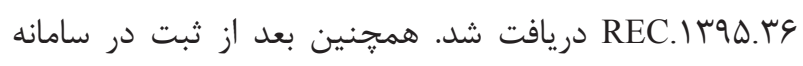

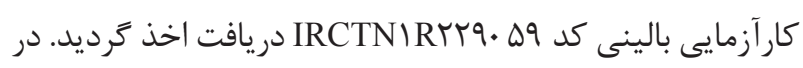

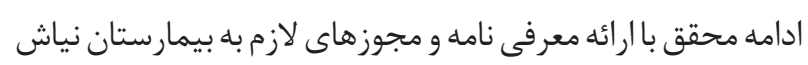

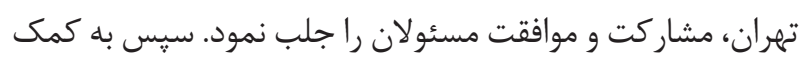

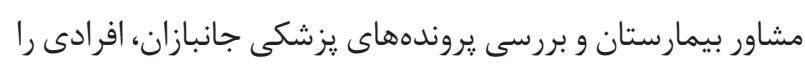

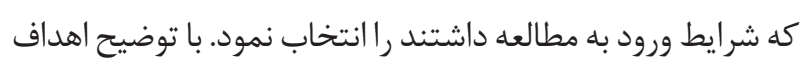
يزوهش و اطمينان از بى خطر بودن اين يزوهش و حفظ كمنامى و

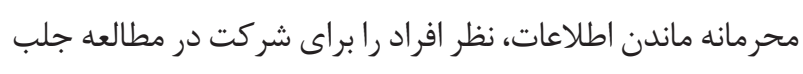

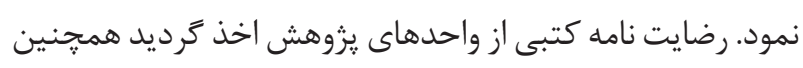
به واحدهاى يزوهش تأكيد شد كه در صورت تمايل مى توانند

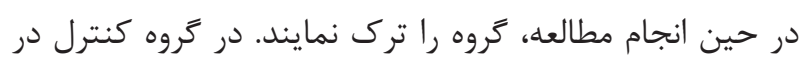
زمان حضور همسران در بيمارستان هيج مداخلهاى انجام نشد.

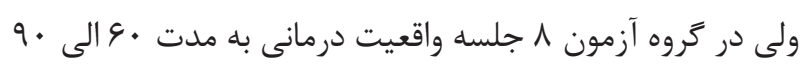

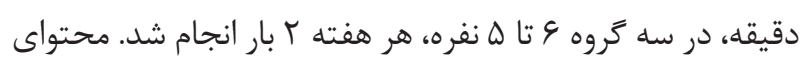

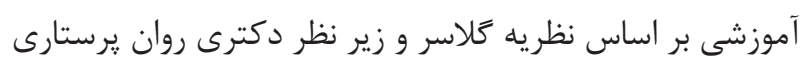

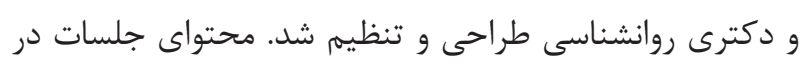

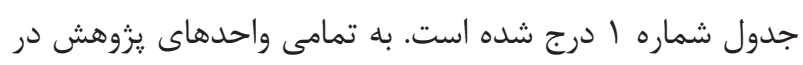

جدول 1 - خلاصه جلسات واقعيت درمانى تروهى

\begin{tabular}{|c|c|}
\hline آشنايى اعضاى گروه با يكديخر درمانخر و شرح هدف از اجراى يزوهش توسط يروهشكر و معرفى اعضاى گروه & جلسه اول \\
\hline بحث و آموزش در خصوص مسئوليت پذيرى و اهميت آن و خحَونكى تعهدات زناشويى & جلسه دوم \\
\hline آموزش در خصوص سازگًارى و انواع سازگًاىى، روشهاى بكارگيرى آن در خانواده و روابط زناشويى & جلسه سوم \\
\hline آموزش در خصوص همدلى و انواع همدلى و نقش زوجين و ساير اعضاى خانواده در همدلى & جلسه سوم \\
\hline آموزش در خصوص نيازهاى اعضاى خانواده و جكونگى كمك به يكديكر در رفع نيازها & جلسه جهارم \\
\hline آموزشهاى مربوط به تعهدات و استفاده از روشهاى سازگارى و برنامهريزىهاى شخصى و خانوادىى & جلسه קنجم \\
\hline آموزش در خصوص روشهاى حل مسئله و برنامهريزى در خصوص سازگًارى با مشكلات & جلسه ششم \\
\hline 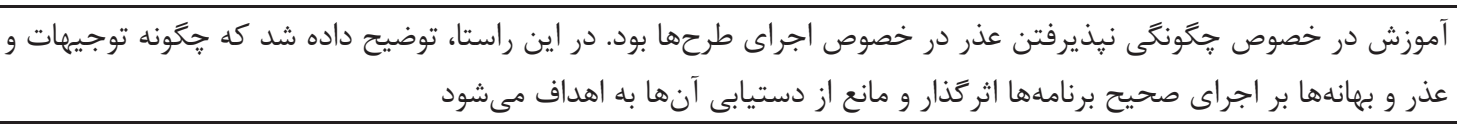 & جلسه هفتم \\
\hline مرورى بر جلسات كذشته و تكميل مجدد يرسشنامه همدلى & جلسه هشتم \\
\hline
\end{tabular}


جدول r - مشخصات جمعيت شناختى همسران جانبازان

\begin{tabular}{|c|c|c|c|}
\hline تروه كنترل & كروه آزمون & & مشخصات دوموگر افيك \\
\hline$\Delta \cdot / K F \pm F / F G$ & $\Delta \cdot / / V \pm r / r V$ & & سن (M+SD) \\
\hline$r(/ .1 \wedge)$ & $\Delta(/ . \mu \cdot)$ & زيردييلم & تحصيلات \\
\hline$q(/ . \mu \Delta)$ & $\Delta(/ . \mu \cdot)$ & دييلم & \\
\hline$\Lambda(/ . Y \vee)$ & $V\left(/ / Y^{c} \cdot\right)$ & دانشخاهى & \\
\hline $14(/ . V I)$ & If (/.Ar) & خانهدار & شغل \\
\hline$\Delta(/ . / 9)$ & $r(\% 11)$ & كارمند & \\
\hline$r \varepsilon / \cdot 1 \pm \Delta / 1 T$ & $r V / I V \pm q / 4)$ & & مدت زمان زندگى مشترك (M+SD) \\
\hline$r q / 41 \pm 1 \cdot / 4 r$ & $r \varepsilon / r \Delta \pm \mid r / 1 \Lambda$ & & 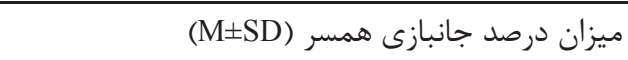 \\
\hline
\end{tabular}

جدول س - تأثير واقعيت درمانى بر همدلى همسران جانبازان دجار اختلال استرس يس از سانحه جنكى

\begin{tabular}{|c|c|c|c|c|c|c|}
\hline اندازه اثر & سطح معنىدارى & مقدارسطح آماره & ميانغين مجذورات & درجه آزادى & مجموع مجذورات & منبع واريانس \\
\hline$\cdot / 49$ & $\mathrm{P}<\cdot 1 \cdot 1$ & $|r / \Delta|$ & $19 T \cdot 1911$ & r & THYI/TH & مدل اصلاح شده \\
\hline$\cdot / \pi q$ & $\mathrm{P}<\cdot 1 \cdot 1$ & $I T / V A$ & IQTT/QV & 1 & IOTT/QV & جداكننده يس آزمون \\
\hline \multirow[t]{4}{*}{.119} & $\mathrm{P}=\cdot / \cdot 1$ & $V / \mu$ & $\wedge \vee \Delta / \Upsilon \wedge$ & 1 & $\wedge \vee \Delta / r \wedge$ & كروه \\
\hline & & & $119 / 19$ & 1 & rVIG/Vq & خطا \\
\hline & & & & re & IDSVAr & جمع \\
\hline & & & & سr & $\varepsilon 9 \Delta \Lambda / \cdot r$ & 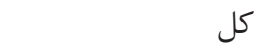 \\
\hline
\end{tabular}

زوجين مى گردد (9 ())، مطالعه ديخر در اين زمينه نشان داد واقعيت درمانى موجب بهبود و تسهيل روابط زناشويى و روابط بين فردى زن و شوهر مى گردد ( • r). همجنين اين روش درمانى مانى سبب كاهش افسردىى زنان ( آY)، كاهش نشخوار فكرى، وسواس فكرى بيماران مبتلا به اختلال استرس يس از سانحه (YT)،

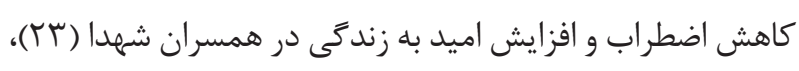
افزايش تعهدات و كاهش دل زد خود كارآمدى، افزايش رضايت از زندگى و شادكامى (ه广، عץ). افزايش مسئوليتيذيرى و افزايش عزت نفس مى همجنين ابن الشريعه و همكارش در مطالعه خود، اثربخشى نظريه واقعيت درمانى كلاسر را بر ارتقاء سلامت عمومى و كاهش طلاق در زوجين را نشان دادند (Y^). از آنجايى كه همسران جانبازان در كنار ايفاى نقش متعدد همجون اداره امور مربوط به كارهاى منزل، مراقبتهاى جسمانى و هيجانى از اعضاى خانواده و ₹اهى تأمين معاش خانواده استرس و مشكلات روانى مختلفى را تجربه مى كنند (و ()؛ نظريه واقعيت درمانى بر

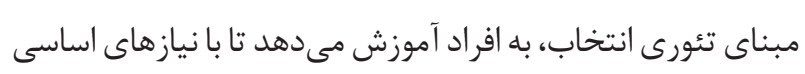

همدلى رانشان نداد (9= • P= P). ولى در زروه آزمون در مقايسه قبل و بعد از مداخله آمون تى زوجى (Paired Sample t Test) اختلاف

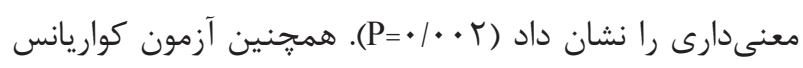
ا با حذف اثر ييش آزمون، اختلاف معنى (Covariance) نشان داد ( P</ P (P) كه نشان دهنده اثربخش بودن مداخله در اين گزوهش مىباشد. (جدول r)

\section{بحث و نتيجه كيرى}

مطالعه حاضر با هدف تأثير واقعيت درمانى بر همدلى همسران جانبازان دجار اختلال استرس يس از سانحه جنَى انجام شد.

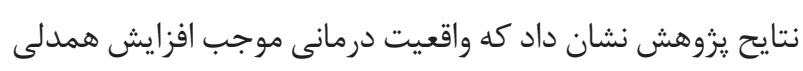

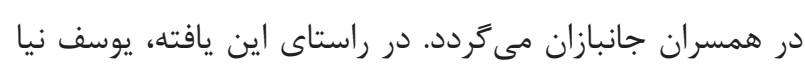
و همكاران در مطالعه خود نشان داد، واقعيت درمانى در مشاوره ازدواج، حل تعارضات زناشويى و خانوادكى مؤثر مىباشد (IV). واقعيت درمانى به عنوانى يك مداخله روانشناختى موجب ارتقاء كيفيت زندگى و رضايت زناشويى در زوجين مى همجنين موجب كاهش ناسازكارىهاى زوجين و بهبود روابط ريط 
تشويق، احترام، اعتماد و يذيرش يكديخر ارتباط بهترى با همديگر

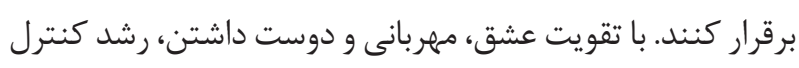

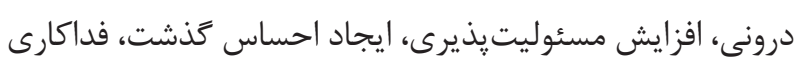

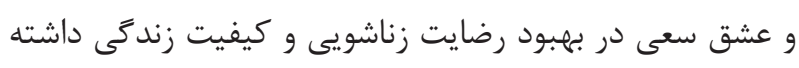

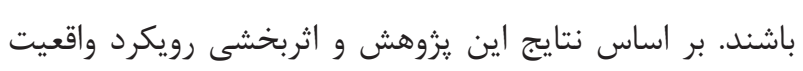
درمانى بر ميزان همدلى همسران جانبازان نياز است كه مسئولين

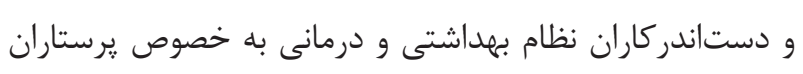

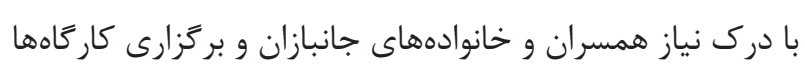
و كلاسهاى آموزشى و جلسات كروه درمانى مبتنى بر واقعيت درمانى ضمن تقويت روابط زناشويى، موجب بهبود كيفيت زندى أنى در خانواده همسران جانبازان شوند.

تشكر و قدردانى

اين مقاله مستخرج از يايانامه كارشناسى ارشد روان يرستارى

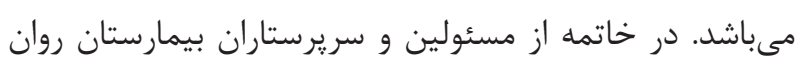
نيايش تهران وابسته به بنياد شهيد و ايثار تران و همجنين ونين همسران

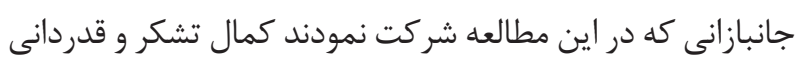

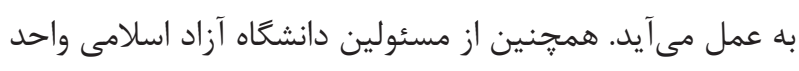
تهران بزشكى تقدير مى تردد.

\section{تضاد منافع}

بدين وسيله نويسندكان تصريح مىنمايند كه هيج كونه تضاد منافعى در خصوص يزوهش حاضر وجود ندارد.

\section{References}

1- Tsai J, Harpaz-Rotem I, Pietrzak RH, Southwick SM. The role of coping, resilience, and social support in mediating the relation between PTSD and social functioning in veterans returning from Iraq and Afghanistan. Psychiatry. 2012; 75(2): 135-49. DOI: 10.1521/psyc.2012.75.2.135.

2- Renshaw KD, Allen E, Carter S, Markman HJ, Stanley SM. Partners' attributions for service members' symptoms of combatrelated posttraumatic stress disorder. Behav Ther. 2014; 45(2): 187-98. DOI: 10.1016/j.beth.2013.10.005

3- Akoondzadeh G, Ebadi A, Nouhi E, Hojjati H. Threatened Health in Women: A Qualitative Study on the Wives of War Veterans with Post-Traumatic Stress. Global J Health Scie. 2017; 9(3): 176-7.
خود آشنا شوند، احساس بهترى نسبت به خود و موقعيتى كه در

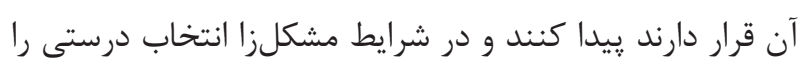

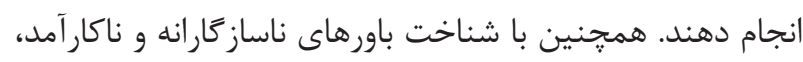
رفتارهاى درست و مناسب را جايكزين نمايند (Y^).

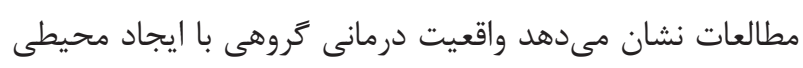

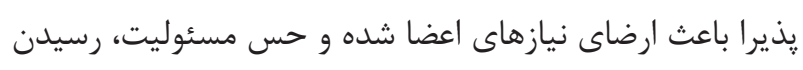

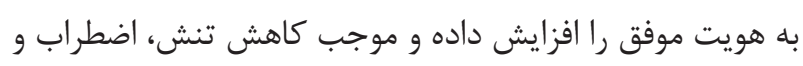

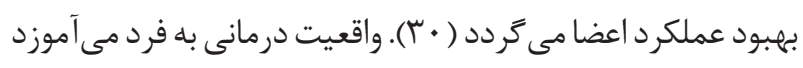
كه براى دستيابى به خواستههايش بايد به كونهاى مؤثر و مطلوب

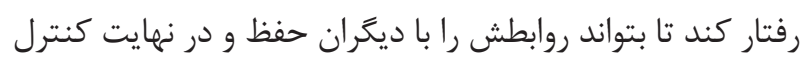
مؤثرى بر محيط خود داشته باشد (آ⿱一). در اين رويكرد مردم

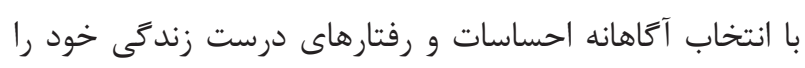
بهتر مى كنند (1) (1) در مجموع مى توان كَفت در واقعيت درمانى

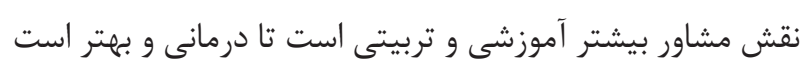

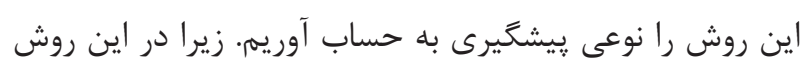
بيشتر بر افزايش تعهد و مسئوليت يذيرى در برنامهريزى رها تها تأكيد

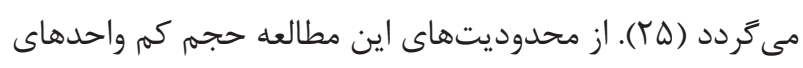

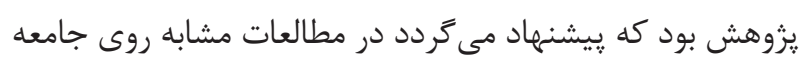
آمارى بيشتر اين مطالعه انجام كيرد.

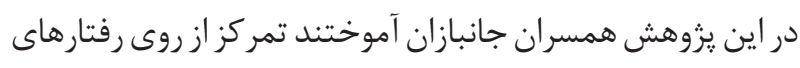

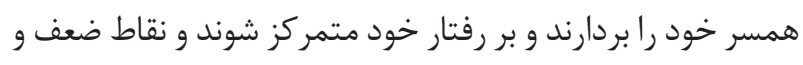

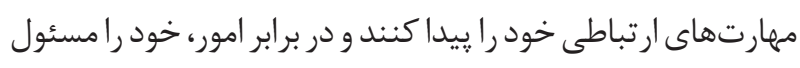

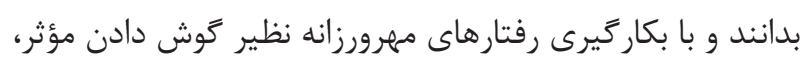

DOI:10.5539/gjhs.v9n3p176

4- Peraica T, Vidović A, Petrović ZK, Kozarić-Kovačić D. Quality of life of Croatian veterans' wives and veterans with posttraumatic stress disorder. Health Qual Life Outcomes. 2014; 12(1): 136.

5- Wolf EJ, Harrington KM, Reardon AF, Castillo D, Taft CT, Miller MW. A dyadic analysis of the influence of trauma exposure and posttraumatic stress disorder severity on intimate partner aggression. J Trauma Stress. 2013; 26(3): 329. DOI: 10.1002/ jts. 21805 .

6- Verdeli H, Baily C, Vousoura E, Belser A, Singla D, Manos G. The case for treating depression in military spouses. J Fam Psychol.2011; 25(4): 488-96. DOI:10.1037/a0024525 
7- Sirati Nir M, Ebadi A, Fallahi Khoshknab M, Tavallaie A. Consequences of living with Posttraumatic Stress Disorder: A Qualitative Study. J Qual Res Health Sci. 2012; 1(2): 92-101. (Persian)

8- Klarić M, Frančišković T, Obrdalj EC, Petrić D, Britvić D, Zovko N. Psychiatric and health impact of primary and secondary traumatization in wives of veterans with posttraumatic stress disorder. Psychiatr Danub. 2012; 24(3): 280-6. PMID: 23013633

9- Moghanloo M, Hosseini S. Prediction of Emotional Empathy in the Wives of Veterans by Cognitive Emotion Regulation Strategies and Resilience. Iran J War Public Health. 2019; 11 (2):93-99. (Persian)

10- Monson CM, Taft CT, Fredman SJ. Military-related PTSD and intimate relationships: From description to theory-driven research and intervention development. Clin Psychol Rev. 2009; 29(8):70714. DOI: 10.1016/j.cpr.2009.09.002. (Persian)

11- ZintyAfkham A, Sohrabi F, Borjali A. The effectiveness of imagery receipting and reprocessing therapy on reduction of subjective units of distress and recurrent images on war disabled with post traumatic stress disorder. J Mil Psychol, 2010; 1(3): 1-12.(Persian)

12- Yambo T, Johnson M. An integrative review of the mental health of partners of veterans with combat-related posttraumatic stress disorder. J Am Psychiatr Nurses Assoc. 2014; 20(1):31-41. DOI: $10.1177 / 1078390313516998$.

13- Abbasi H, Ahmadi SA, Fatehi zadeh M, Bahrami F. The Effect of Glaser's Reality Therapy on Personal Commitment of Couples. Family Pathology, Counseling \& Enrichment Journal. 2016; 2(1): 40-65. (Persian)

14- Sedaghat M, Sahebi A, Shahabi Moghaddam S. The Effectiveness of Individualized Reality Therapy on Major Depression Patients with Suicide Attempt History. Journal of Police Medicine. 2017; 5(5): 317-27. (Persian)

15- Mohammadi S, Ghamari M, Jaafari A. The effectiveness of group counseling based on reality therapy Reduce conflict in the parent of the same sex school girls. Journal of Women and Family. 2013; 7(23): 317-27. (Persian)

16- Ghorbani N, Watson PJ, Hamzavy F, Bart L. Self-Knowledge and Narcissism in Iranians: Relationships with Empathy and SelfEsteem. Current Psychology. 2010; 29(2): 134-143. DOI: 10.1007/ s12144-010-9079-5. (Persian)

17- Yoysefikia M, Khoshkonesh A, Falahzadeh H. The effectiveness of reality therapy to decreasethe marital conflict and despair in women with multiple sclerosis. Armaghane danesh. 2018; 23(3): 364-77.(Persian)

18- Dizjani F, Kharamin Sh. Reality therapy effect on marital satisfaction and women's quality of life. Armaghane danesh. 2016; 21(1): 187-99. (Persian)

19- Boromand R, Sadeghifard M, Samavi SA. The Effectiveness of group counseling based on the choice theory on reducing marital conflicts. Am J Life Sci Res 2013; 1(1):187-99

20- Ramzi Eslambooli L, Alipour A, Sepehri Shamloo Z, Zareh H. The Effectiveness of Group Therapy based on Reality Therapy on Rebuild of Relationship Beliefs in Working Married Women of Mashhad. Family Research. 2015; 10(4): 493-509. (Persian)

21- Toozandehjani H, Soltanzadeh Mezreji H. Efficacy of group reality therapy on depression in infertile women before treatment with assisted reproductive techniques IUI. J Res Behave Sci 2014; 12(2): 184-93. (Persian)

22- Prenzlau S. Using Reality Therapy to Reduce PTSD-Related Symptoms. Int j real therapy 2006; 25(2): 23-9.

23- Pasha GH, Amine S. Effect io expectancy and anxious wives of martyrs. New finding in the Journal of Psychology. 2008; 3(9): 37-51. (Persian)

24- Seadatee shamir A, Najmi M, Haghshenas rezaeeyeh M. The Effectiveness of Reality Therapy Training on Marital Engagement and Marital Engagementin Married Students in Azad University. Journal of of research in medical system. 2018;12(Special Issue). 653-69. (Persian)

25- Gharibpour S, Hojati H. The effect of reality therapy on selfefficacy in mothers of children with Down syndrome. Iranian Journal of Nursing Research. 2019; 13(6): 63-7. (Persian)

26- Ghorbanalipour M, Najafi M, Alireza Z. Effectiveness health on happiness and hope in fact divorced women. Journal of a psychotherapy and counseling family. 2014; 4(2): 298-304. (Persian)

27- Amiri M, Aghamohammadian Sherbaf H, kimeie A. Effectiveness of reality therapy on locus of control and coping strategies. Thought \& Behavior in Clinical Psychology. 2012; 6(24): 50-60. (Persian)

28- Ebnosharieh J, Aghili SM. Effectiveness of group based reality therapy based on Glasser choice theory on the general health and obsessive beliefs of divorced women. Journal of Gorgan University of Medical Sciences. 2019; 20(4):53-60. (Persian)

29- Saghaian AS, Bahmani B, Eskandari M, Asgari A. Effectiveness reality therapy being of female-headed households. Research in Clinical Psychology and Counseling. 2016; 5(2). (Persian)

30- Asmkhany Akbarnejad H, Etemadian A, Nasiri Nejad F. Effectiveness of reality therapy in group exercise on anxiety in women. Journal of Psychological Studies. 2014; 10(2):75-9. DOI: 10.22051/psy.2014.1773. (Persian)

31- Moshirian Farahi SM, Moshirian Farahi SMM,Aghamohammadian Sharbaf H R, Sepehri Shamloo Z. The Effectiveness of Group Reality Therapy Based on Choice Theory on Quality of Life in People with Aggression. Iranian Journal of Psychiatric Nursing. 2017; 5 (1):47-53. DOI: 10.21859/ijpn-05017. (Persian) 